\title{
JUEGO DE GENERACIONES. APUNTES SOBRE EL NUEVO PAISAJE POLÍTICO CHILENO*
}

\author{
Cristóbal Bellolio \\ Universidad Adolfo lbáñez
}

\begin{abstract}
RESUMEN: Este ensayo propone mirar con atención el recambio generacional de las élites políticas que ha tenido lugar en los últimos años en Chile. En lo central, sostiene que la línea divisoria del plebiscito de 1988 - con coaliciones y partidos alineados en torno al Sí y al No- ha perdido fuerza como determinante de la pertenencia política. La generación que no vivió la experiencia autoritaria y adquirió conciencia política en democracia se organiza, en cambio, asegura el autor, en torno a una oferta electoral propia.

Palabras Clave: transición, Frente Amplio, Evópoli, oferta electoral, paisaje político.
\end{abstract}

Cristóbal Bellolio. Abogado y licenciado en ciencia política de la Pontificia Universidad Católica de Chile. Doctor en filosofía política por la University College London, Reino Unido. Profesor asistente de la Escuela de Gobierno de la Universidad Adolfo Ibáñez. Email: cristobal.bellolio@uai.cl.

* Las ideas centrales de este trabajo fueron presentadas como comentario a la publicación del estudio "Juventud y política a 30 años del plebiscito", de la investigadora del Centro de Estudios Públicos Loreto Cox, en octubre de 2018. Agradezco a Kenneth Bunker y Stephanie Alenda por sus observaciones a una versión preliminar del texto, así como a Patricio Navia y Sergio Toro por conversaciones al respecto. Agradezco también los comentarios de los árbitros anónimos y editores de la revista Estudios Públicos. 


\section{CHANGE OF GENERATIONS. NOTES ON THE NEW POLITICAL LANDSCAPE IN CHILE}

ABSTRACT: This essay sets out to look closely at the generational shift of recent years in Chile's political elites. Its central argument is that the watershed of the 1988 plebiscite, when parties and coalitions aligned around Yes and No, has become less important as a determinant of political allegiance. Instead, the author argues, the generation that did not go through the authoritarian experience but grew to political awareness under democracy has organized around an electoral platform of its own devising.

Keywords: transition, Frente Amplio, Evópoli, electoral platform, political landscape.

\section{INTRODUCCIÓN}

ay diversas razones que explican el cambio en los sistemas de partidos y en el mapa político en general. Sin desmerecer la influencia de los clivajes sociológicos tradicionales ni de las teorías institucionalistas, el presente ensayo se concentra en la variable del recambio generacional de las élites políticas que ha tenido lugar en los últimos años en Chile. En lo central, sostiene que la línea divisoria del plebiscito de 1988 pierde fuerza como determinante de la pertenencia política, en la medida en que una generación que no vivió la experiencia autoritaria adquiere conciencia política en democracia y se organiza en torno a una oferta electoral propia. Si bien esta variable no es suficiente para subsumir las alineaciones políticas previas ni para determinar la posición relativa de todos los actores, sí entrega claves relevantes para entender la emergencia de nuevas fuerzas y la conformación del paisaje político chileno post-transición.

Este paisaje, encarnado en el sistema de partidos que emergió a partir del plebiscito de 1988, sufrió importantes modificaciones en la elección presidencial y parlamentaria de 2017. La principal de ellas apunta a la fragmentación de un sistema que hasta entonces era dominado sin contrapesos por dos grandes coaliciones. Esta vez, más de cuatro coaliciones obtuvieron más del 10 por ciento de los votos, revelando un fraccionamiento superior al que tenía Chile previo a 1973 (Bunker 2018). Por primera vez en más de medio siglo hubo más de diez partidos relevantes compitiendo, con más de siete logrando representación 
en el Congreso. Las elecciones del 2017 marcan, además, un hito en términos de recambio de las élites políticas de la transición. De los 155 diputados que obtienen un escaño en la Cámara Baja, 92 son debutantes. En este sentido, destaca la irrupción del Frente Amplio, que obtiene veinte diputados y un senador, en su mayoría jóvenes que no votaron o no habían nacido para el plebiscito de 1988.

Este cambio en el paisaje político chileno puede intentar explicarse desde una perspectiva institucionalista (Duverger 1954) o bien sociológica (Lipset y Rokkan 1967). Según la primera, el sistema de partidos se ordena dependiendo de las reglas electorales, las que funcionan como incentivos o disuasivos para la formación de partidos y coaliciones. El sistema de partidos de la transición, según la teoría institucionalista, respondía principalmente a los incentivos y disuasivos del sistema electoral binominal establecido por la dictadura (Guzmán 1993). En las elecciones de 2017 coinciden, por primera vez, las dos grandes reformas que experimentó el sistema electoral. Por un lado, el mecanismo de inscripción automática y voto voluntario, que entró en vigor en las municipales de 2012. Por el otro, la sustitución del sistema binominal por uno proporcional corregido, promulgado en 2015. Estas nuevas reglas del juego explicarían, desde la perspectiva institucionalista, el nuevo paisaje político: su fragmentación sería el resultado de la aplicación de reglas que entregan más posibilidades de obtener escaños a terceras fuerzas. ${ }^{1}$

La perspectiva sociológica, en cambio, sugiere que los sistemas de partidos se organizan en torno a ciertos clivajes sociológicos que dividen profundamente a la población, como es el caso de la religión o la clase. Dichos clivajes habrían explicado el sistema de partidos chileno hasta 1973 (Scully 1992; Valenzuela 1995). Sin embargo, el plebiscito de 1988 habría sido capaz de absorber dichos clivajes en una nueva "fisura generativa" que dividió a los chilenos en dos campos: el democrático y el autoritario (Tironi y Agüero 1999). Aunque se discute si este reordenamiento obedece a la definición tradicional de clivaje o bien sólo representa el resultado de posicionamientos políticos contingentes (Valenzuela 1999), la mayoría de la literatura coincide en que las actitudes de los chilenos frente a la dictadura son claves para entender el paisaje político que

${ }^{1}$ Tal como señala Bunker (2018), mientras entre 1989-2013 fue necesario obtener el 33 por ciento de los votos de una unidad electoral para asegurar un escaño, en 2017 fue necesario sólo el 25. 
emergió a fines de los ochenta, se consolidó durante la transición y logró extender su vigencia por más de veinticinco años (Carey 2002; Torcal y Mainwaring 2003; Ortega 2003; Garrido y Navia 2005; Luna 2008). Este artículo no se pronuncia si acaso la fisura de 1988 corresponde a un clivaje en el sentido original de Lipset y Rokkan. Como observa el propio Valenzuela (1999), un sistema de partidos se puede transformar a partir de ciertas circunstancias políticas y no necesariamente a partir de nuevas fisuras sociales estructurales. Lo que parece evidente es que el plebiscito de 1988 constituye un hito de socialización política para toda una generación, que determina fuertemente sus preferencias sucesivas y entrega coordenadas nítidas para entender el sistema de partidos chileno.

En este sentido, esta indagación propone que, más allá de los factores institucionales, el paisaje político chileno que emerge en 2017 se relaciona con la entrada definitiva de la generación post-Pinochet a la arena electoral, a través de partidos y coaliciones propias que desafían a los partidos y coaliciones históricamente asociadas con la fisura democrático-autoritaria. A medida que el hito originario de dicha fisura - el plebiscito de 1988 - se difumina en el tiempo, una nueva generación que adquiere conciencia política en democracia reclama el derecho de competir electoralmente con colores propios, en parte debido al fracaso de la propia generación de la transición de alimentar procesos de renovación internos. En este sentido, este artículo sostiene que las movilizaciones de 2011 funcionan como hito formativo para las élites políticas de esta nueva generación, que recién en 2017 se traduce en un relativo éxito electoral que transforma parcialmente el sistema de partidos. En resumen, se argumenta, la variable generacional, si bien carece de las características socio-tectónicas de los clivajes tradicionales, ha influido en el cambio parcial del paisaje político chileno, diluyendo el impacto del proceso de socialización previa ligado a la experiencia autoritaria como elemento explicativo de la pertenencia partidista y coalicional.

\section{DE LOS CLIVAJES TRADICIONALES A LA FISURA DEMOCRÁTICO-AUTORITARIA}

Según Lipset y Rokkan (1967), los sistemas de partidos se organizan en torno a ciertos clivajes sociológicos estructurales. Tomando ejemplos de Europa occidental, concluyeron la existencia de cuatro 
tipos de clivajes: centro-periferia, Estado-iglesia, urbano-rural y trabajadores-empleadores. Aunque estos clivajes no siempre determinan sistema de partidos, una vez que lo hacen, sostenían los autores, tienden a petrificarlo. Similares clivajes habrían determinado el sistema político chileno. Así, en el siglo XIX habría predominado la fisura religiosa, que dividió entre partidos clericales y seculares. El siglo XX se habría inaugurado con la incorporación del clivaje de clase y el debut de los partidos obreros. Los principales partidos decimonónicos quedaron entonces a la derecha del eje. Poco después, en tiempos de migración del campo a la ciudad, el Partido Demócrata Cristiano reclamó la representación de la ruralidad, incorporándose como tercero en discordia entre la derecha capitalista y la izquierda marxista. Aunque, en rigor, el sistema chileno pasó a ser multipartidista, hacia 1973 ya se había configurado un eje de tres tercios en términos coalicionales. Basándose en la experiencia comparada, algunos sugirieron que, una vez terminada la experiencia autoritaria, el sistema de partidos chileno retomaría las características previas al golpe, pues la desmovilización forzada habría dejado el anterior paisaje político en estado de hibernación (Scully y Valenzuela 1993; Valenzuela 1995).

Tironi y Agüero (1999) disputan esta tesis de la continuidad del sistema de partidos pre-1973 y argumentan, en cambio, que el plebiscito de 1988 representa una nueva "fisura generativa" que divide políticamente a la población entre dos campos: democrático o autoritario. El viejo sistema de partidos no reemergería. Un nuevo paisaje se había formado. El referido plebiscito había hecho más que poner término al régimen de Pinochet; había fundado un clivaje que resumía de mejor manera las identidades ideológicas y lealtades afectivas de la población. A un lado quedaron los opositores al régimen, al otro lado, sus partidarios. Dicho clivaje se expresaba en un sistema de partidos organizado en torno a dos grandes coaliciones, herederas del No y del Sí, respectivamente. Aunque dicho clivaje ha sido recalificado como estrictamente político (Ortega 2003; Bargsted y Somma 2016), Tironi y Agüero lo incluyen dentro de la amplia categoría sociológica, para distinguirlo de los clivajes institucionales que surgen a partir de cambios en las reglas electorales. Con independencia del innegable efecto del sistema binominal, la tesis de Tironi y Agüero es que la experiencia autoritaria marcó a fuego a toda una generación "que construyó en esta etapa su 
marco de referencia político" $(1999,157)$, y en consecuencia construyó partidos y coaliciones afines a dichos marcos.

Para temperar esta tesis, algunos sostuvieron que la religión y la clase seguían siendo importantes para explicar las preferencias políticas de los chilenos (Valenzuela, Scully y Somma 2007; Raymond y Feltch 2014). En cualquier caso, si bien es plausible que los clivajes clásicos de clase y religión hayan coexistido con la "fisura generativa" de 1988, hay indicios de que los primeros se debilitaron en la transición. Prueba de ello sería la aparición de una derecha "popular", por un lado, y la consolidación de una coalición de centroizquierda que aglutinó a humanistas laicos y humanistas cristianos, por el otro. De manera interesante, el supuesto clivaje democrático-autoritario estaría mostrando también signos de declive (Bargsted y Somma 2016). No es un fenómeno inesperado: Torcal y Mainwaring (2003) anticiparon que el eje democrático-autoritario perdería fuerza a medida que el tiempo fuera borrando las memorias de la dictadura, una nueva generación de votantes entrara en escena y la derecha lograra distanciarse exitosamente de Pinochet.

Como teoría general, Torcal y Mainwaring (2003) sugirieron también que los factores determinantes del paisaje político dependen más de la agencia de los actores y las élites que de la manera en que se despliegan las grandes divisiones sociales. Es decir, que la morfología del sistema de partidos no siempre responde a una lógica "de abajo hacia arriba", sino que muchas veces queda determinada a partir de acciones "de arriba hacia abajo". ${ }^{2}$ En el caso chileno, esta teoría permite argumentar que la vigencia del eje democrático-autoritario está relacionada con el interés de las propias élites políticas en su instalación y persistencia. Su debilitamiento, en tanto, estaría correlacionado con la incapacidad de dichas élites de controlar la morfología del paisaje político. En este marco, la élite de la transición habría perdido parte importante de su capacidad de insistir en la fisura de 1988 cuando el padrón electoral

${ }^{2}$ Que las transformaciones del paisaje político sean animadas por una élite "de arriba hacia abajo" no las transforma necesariamente en institucionales, como podría pensarse. Por variables institucionales, este artículo entiende estrictamente cambios en las reglas del juego, como reformas electorales. Por supuesto, las élites responden a dichos cambios adecuando su oferta política, pero la teoría de la agencia política es relativamente independiente de dichos cambios. Aun sin cambios en el sistema electoral, las élites políticas pueden insistir o desistir de ciertas narrativas, dependiendo de su conveniencia. 
deja de representar casi exclusivamente al electorado del plebiscito tras la reforma de $2012 .^{3}$

Del mismo modo, la praxis política sería la responsable de la erosión de ciertos clivajes sociales que pierden utilidad. Así, por ejemplo, la Concertación de Partidos por la Democracia que nació a fines de los ochenta minimizó deliberadamente la importancia del clivaje de clase que históricamente había definido a la izquierda en el siglo XX. ${ }^{4}$ Tampoco, ni entonces ni después, fue relevante hablar de religión. En cambio, consistente con la promesa de su nombre, la Concertación intensificó el relato de la reconquista de la democracia, un relato efectivo con el que el adversario estaba plenamente identificado y era electoralmente minoritario: en el nuevo paisaje político, eran dos de los viejos tercios (izquierda y centro) contra uno (derecha). Si el objetivo de la Concertación era continuar como la coalición política dominante en Chile, evocar el plebiscito de 1988 era una estrategia ganadora. Por lo anterior, sus dirigentes invirtieron en la persistencia de dicha división.

En ello contribuyó que el propio Augusto Pinochet continuara siendo protagonista durante los noventa. Su detención en Londres, diez años después del plebiscito, sirvió para reavivar el ordenamiento democrático-autoritario. El ex dictador muere en 2006. En la primera elección presidencial sin Pinochet, gana finalmente la derecha. Durante ese gobierno, se termina la Concertación. Pero renace en 2013 con otro nombre - Nueva Mayoría - y una composición muy similar, salvo que

${ }^{3}$ Tal como observan Cox y González (2016), en las elecciones de 2013 hubo cerca de 30 por ciento de recambio en los votantes. En cuanto a la composición etaria, señalan que en 2013 "hubo un incremento neto en la participación electoral de los chilenos entre 18 y 34 años, y una pérdida neta de votantes mayores de 35 años, la cual se concentra principalmente en los votantes de entre 40 y 55 años de edad. Como consecuencia, el sesgo etario que se observaba en el padrón, al momento de establecerse la reforma, se redujo importantemente" $(2016,2)$.

${ }^{4}$ Torcal y Mainwaring (2003) sostienen que el clivaje de clase en Chile se ha debilitado por razones estructurales y otras ligadas a la acción política. Respecto de las primeras, sugieren que los clivajes tradicionales tienden a declinar cuando se resuelven los conflictos sociales que les dieron origen. Cabe preguntarse entonces si el fenómeno de una creciente clase media en Chile ha terminado por diluir el clivaje de clase. Respecto de las segundas, los autores recuerdan que la dictadura desmovilizó sindicatos y organizaciones obreras ligadas a la izquierda. Sin perjuicio de lo anterior, insisten, los líderes de la Concertación evitaron conscientemente los debates sobre clase y redistribución para ahuyentar los miedos que éstos generaron en las décadas de los sesenta y setenta. 
integra por primera vez al Partido Comunista. El único factor común de las candidaturas que participaron en su primaria presidencial de 2013 fue precisamente "la oposición a la figura de Pinochet, las violaciones a los derechos humanos, el debate en torno al sistema político institucional y al modelo económico heredado del régimen militar" (Aubry y Dockendorff 2014, 19). Del mismo modo, siguiendo la tesis de la agencia política en la activación y desactivación de los clivajes, Aubry y Dockendorff (2014) destacan los esfuerzos de la élite política de centroizquierda por reponer emocionalmente el eje democrático-autoritario a propósito de la conmemoración de los 40 años del golpe militar.

La derecha, en cambio, ha intentado en diversas ocasiones emanciparse de su sombra autoritaria. El primer intento sistemático fue la candidatura presidencial de Joaquín Lavín en 1999, que buscó cambiar el eje de la discusión política hacia la solución práctica de los problemas cotidianos de la ciudadanía. El progresivo deterioro reputacional de la dictadura, en especial después de la detención de Pinochet en Londres y el caso Riggs, obligó a los líderes de la derecha a desactivar un clivaje político crecientemente incómodo. Aun así, la agenda programática de la derecha chilena durante la transición estuvo siempre asociada a la defensa de la obra del régimen militar y al mantenimiento de sus instituciones. Aunque la fisura generativa de 1988 los condenó a ser minoría, sus dirigentes nunca estuvieron del todo descontentos: en el escenario pre-1973 eran un tercio; en el nuevo escenario - al menos, en términos de representación parlamentaria por efecto del sistema binominal — eran prácticamente la mitad.

En síntesis, el sistema de partidos chileno que emergió del plebiscito de 1988 quedó determinado por la fisura democrático-autoritaria, absorbiendo los clivajes sociales anteriores. El nuevo paisaje político se consolidó por la acción de las élites políticas que invirtieron en su vigencia, sin perjuicio del efecto del sistema electoral en su mantenimiento. Sin embargo, el nuevo ordenamiento no sería eterno. Llegaría el momento en el cual perdería su capacidad de movilizar y diferenciar entre votantes. El nuevo sistema de partidos no se configuraría necesariamente a partir de la reaparición de las viejas o la emergencia de nuevas grietas estructurales del calado descrito por Lipset y Rokkan (1967), sino por nuevas temáticas que nuevas élites serán capaces de presentar como determinantes para fijar la pertenencia política de las nuevas generaciones (Torcal y Mainwaring 2003). El propio Valenzuela (1999) reconoce que el sistema de partidos que emerge del período au- 
toritario es el quinto desde que surgieron partidos duraderos a fines del gobierno de Manuel Montt, y que la mayoría de estas transformaciones se han debido a circunstancias políticas y no al surgimiento de nuevas fisuras sociales. Un sexto reordenamiento podría darse en el mismo registro. En Europa, al menos, las divisiones que estarían determinando los nuevos sistemas de partidos ya no tienen esas características tectónicas. ${ }^{5}$ Lo relevante es que sean suficientes - ya sea por sí mismas o en combinación con otras - para explicar la configuración de un sistema de partidos. La fisura de 1988 fue suficiente para explicar la política chilena desde el retorno a la democracia. Hasta ahora.

\section{A FALTA DE RENOVACIÓN, REEMPLAZO}

El plebiscito de 1988 contó con una exuberante participación electoral que superó el 90 por ciento de la población habilitada para votar. Pero luego fue decreciendo dramáticamente. Tomando en cuenta el porcentaje de votos emitidos en la primera vuelta de las elecciones presidenciales, sobre el total de la ciudadanía habilitada para sufragar, en 1989 votó el 84,2 por ciento; en 1993 el 81,5; en 1999 el 71,8; en 2005 el 63,7; en 2009 el 59,6, y en 2013 el 49,3. En la segunda vuelta entre Michelle Bachelet y Evelyn Matthei, la participación electoral alcanzó un mínimo histórico de 42 por ciento. Aunque era esperable un proceso de normalización de la participación después del intenso hito plebiscitario de 1988, éste ocurrió a un ritmo muy acelerado en términos comparados (Navia 2004). De la epopeya pasamos rápidamente a la normalización, para caer finalmente en un cuadro de relativa desafección electoral, que se agudiza en los jóvenes (Toro 2008).

La explicación más recurrente del fenómeno apunta a que las nuevas generaciones, que se fueron incorporando formalmente a la ciudadanía después del retorno de la democracia, simplemente dejaron de inscribirse en los registros electorales. Es decir, los jóvenes se restaron del proceso. Si bien existe cierto consenso en que la población adulta tiende a participar más que la población joven (Smets y Van Ham

${ }^{5}$ En un reciente artículo, por ejemplo, Hooghe y Marks (2018) expanden la teoría de Lipset y Rokkan al sugerir que en Europa ya es posible identificar un nuevo clivaje transnacional motivado por los debates sobre inmigración e integración regional. 
2013), para el caso chileno esta hipótesis parece insuficiente. En 1988, sin ir más lejos, los jóvenes fueron protagonistas. Más de un tercio del padrón tenía menos de 30 años. Por otro lado, a medida que pasaban los años, la abstención se fue extendiendo hacia segmentos etarios mayores de treinta años (Toro 2008). Por lo anterior, se especula que el fenómeno tiene que considerar los distintos ciclos políticos que enfrentan las distintas generaciones. En esta hipótesis, la generación del plebiscito demuestra una predisposición mayor a participar que las generaciones que no alcanzaron a votar en el plebiscito (Toro 2008; Contreras y Navia 2013; Bargsted, Somma y Muñoz 2018). La razón, se plantea, está ligada a la profundidad de la experiencia autoritaria, así como a la potencia emotiva del hito que le puso término y reinauguró la democracia.

En este mismo lapso, el descenso en los niveles de participación electoral fue acompañado de un descenso en el grado de identificación política con los partidos y las coaliciones que surgieron de la fisura de 1988. Chile destacaba por la baja volatilidad de su sistema de partidos, especialmente en el contexto latinoamericano, pero la ciudadanía se sentía cada vez menos representada por ellos. Esta fue la llamada excepcionalidad chilena: aunque los partidos se convirtieron en instituciones con bajísima legitimidad social, este mínimo respaldo no se tradujo en alta volatilidad y desinstitucionalización del sistema (Luna y Altman 2011; Toro 2016). En un principio, esto no fue problemático para los partidos y las coaliciones de la transición, pues el padrón electoral - todavía con inscripción voluntaria y voto obligatorio- quedó biográficamente anclado al clivaje democrático-autoritario. Es decir, la élite política de la transición disfrutó del congelamiento del electorado. En otros términos, la oferta se conformó con la demanda original, sin experimentar la necesidad de atraer a una nueva demanda.

Esta situación produjo un desacople entre el discurso de las élites políticas de la transición y la experiencia histórica de las generaciones que adquirieron conciencia política en democracia. Estas últimas se habrían sentido progresivamente "ajenas" al marco de referencia que determinó la pertenencia política de sus padres y abuelos, y, en consecuencia, progresivamente alienadas del sistema de partidos que lo traduce (Bellolio 2013). De acuerdo con la tesis de la agencia política, los sistemas de partidos que dependen de hitos políticos retrospectivos se juegan su subsistencia en la capacidad de las élites de asegurar su continuidad. Pero, justamente por la profundidad de la experiencia autoritaria chilena, se hizo difícil que las élites de la transición pudieran transmitirla a las nuevas generaciones. 
Por su parte, esta élite hizo lo posible por extender su permanencia en la primera línea de sus respectivos partidos y coaliciones. Al aspecto permanente de la psicología humana que nos aferra al poder, en el caso chileno hay que añadir el cuadro de ansiedad política de una generación que fue privada de actividad partidista formal durante 17 años. ${ }^{6}$

Por razones como las anteriores, a los partidos de la transición les costó llevar adelante procesos de renovación generacional interna, agudizando la crisis de representatividad por "ajenidad". Según esta tesis, la legitimidad cultural de los partidos está indisolublemente asociada a su capacidad de encarnar los marcos de referencia de las respectivas generaciones. Los partidos que duran décadas lo hacen porque son capaces de renovar sus elencos dirigentes cada cierto tiempo. En Chile, hasta hace muy poco, las dirigencias que emergieron del período autoritario se negaron a reconocer que existía una creciente demanda por renovación generacional. ${ }^{7}$ A falta de renovación, sin quererlo incentiva-

${ }^{6}$ Tal como ha reconocido Enrique Correa, la suya es "probablemente la generación de más larga vigencia en la historia, que hunde sus raíces en la Patria Joven y también jugó un rol importante y a veces decisivo en los gobiernos de Eduardo Frei Montalva y Salvador Allende, y encabezó la lucha contra la dictadura". Fuente: https:/www.emol.com/noticias/Nacional/2016/12/03/833935/Enrique-Correa-Alestigmatizar-a-Lagos-se-estigmatiza-a-quienes-participamos-de-la-transicion.html. Uno de los mejores ejemplos de la resistencia de la generación de Correa a ceder espacios a las nuevas generaciones ocurrió en la antesala de las elecciones parlamentarias de 2013. En la ocasión, el naciente movimiento Revolución Democrática anunció su intención por competir por una diputación en Talca. El diputado incumbente desde 1990, Sergio Aguiló, reaccionó refiriéndose a ellos como un "grupito de jóvenes acomodados" e "hijos de papá", acusándolos además — por la osadía de desafiarlo- de "denostar más de cuarenta años de lucha", preguntándoles si acaso "sabrán lo que fue la dictadura". Fuente: https://www.elmostrador.cl/noticias/ pais/2013/04/22/aguilo-trata-de-hijos-de-papa-a-jackson-y-revolucion-democraticaen-disputa-por-cupos-a-diputados-en-talca/.

${ }^{7}$ La primera campanada de alerta vino con la campaña presidencial de Marco Enríquez-Ominami en 2009. Entonces, el columnista Héctor Soto lo llamó "el candidato inesperado", resumiendo el desconcierto de su generación. Con apenas 36 años, ME-O irrumpió como una carta de renovación que trascendía la división plebiscitaria. Sus adversarios tomaron nota y se apuraron a incorporar figuras jóvenes a sus equipos de campaña. Aunque Tironi (2010) sostiene que la necesidad del recambio generacional aún no estaba en la agenda cuando Eduardo Frei nombró a Sebastián Bowen, de apenas 27 años, como coordinador de su campaña, para entonces ya se publicaban decenas de columnas y piezas de opinión que alertaban sobre la necesidad de "renovar la política" (Bellolio 2013). La generación del plebiscito no estaba leyendo con atención el escenario. 
ron la vía del reemplazo (Bellolio 2013). Según la teoría del reemplazo, cuando fracasa la renovación interna, las generaciones más distantes del hito que origina la morfología partidaria se rebelan contra el sistema de partidos y forman sus propias estructuras, afines a su propia experiencia histórica. Esto es precisamente lo que habría ocurrido en Chile: las nuevas generaciones que adquirieron conciencia política en democracia se vieron excluidas de la conversación 88 céntrica, y sus élites políticas se movilizaron para construir sus propias organizaciones partidarias con el fin de competir contra los partidos de la transición.

A diferencia de la vía de la renovación, la estrategia de reemplazo requirió de un hito originario, un sucedáneo que jugara un rol similar al que jugó el plebiscito de 1988. Ese hito fueron las movilizaciones de 2011. Las generaciones post-Pinochet, nacidas en los ochenta y principios de los noventa, participaban al fin de un suceso político del cual eran protagonistas. Esta coyuntura les permitió emanciparse de una épica ajena y generar una nueva, y en torno a ella fijar renovadas coordenadas de pertenencia ideológica y afectiva. Es posible que dicho hito se estuviera fraguando desde 2006, cuando millares de escolares salieron a las calles y obligaron al primer gobierno de Michelle Bachelet a responder políticamente con cambios de gabinete y reformas al modelo educacional. Sin embargo, para todos los efectos simbólicos relevantes, la presentación en sociedad de una nueva generación auténticamente post-plebiscito tuvo lugar en 2011. Podría retrucarse que las movilizaciones de 2011, si bien reflejaron una efervescencia inusual, no pueden compararse con el impacto dramático que tuvo el plebiscito de 1988. Eso es objetivamente cierto. Pero, para la generación que no vivió el quiebre de la democracia ni su posterior recuperación, la experiencia de 2011 aparece como suficiente en tanto hito movilizador. En el valle de la desafección por el cual transitaba Chile se advierte un peak de efervescencia en torno a esos años. ${ }^{8}$ En la misma línea, Bargsted, Somma

${ }^{8}$ Según el informe 2014 del Proyecto de Opinión Pública de América Latina (LAPOP, por su sigla en inglés), de la Vanderbilt University, durante los años 2011 y 2012 en Chile se observó un aumento considerable en el número de personas, especialmente jóvenes, que participaron en actividades de carácter político, ya sea marchas o protestas. Puesto que dicha participación aún no tenía traducción institucional, se ha sostenido que la intensidad del movimiento estudiantil de la época demuestra que la despartidización y la politización pueden ir de la mano (Bidegaia 2016). 
y Muñoz (2018) sostienen que la cohorte 1991-1995, una de las protagonistas de las movilizaciones estudiantiles de 2011, registra un alza en los niveles de participación respecto de cohortes anteriores.

Se trata de la generación que nace entre 1981 y 1999. Son los millennials chilenos, que tenían entre 12 y 30 años para las movilizaciones de 2011. Es aproximadamente el rango que Krosnick y Alwin (1989) llaman los “años impresionables". Así como la generación de Sebastián Piñera —nacido en 1949- y Michelle Bachelet — nacida en 1951 - adquirió conciencia política en los tiempos que culminaron abruptamente con el golpe militar, la generación de José Antonio Kast — de 1966- y Álvaro Elizalde — de 1969- hizo lo propio a partir de la efervescencia política que rodeó el plebiscito de 1988. Las movilizaciones de 2011 fueron el hito catalizador para la generación de Giorgio Jackson — de 1987- y Camila Vallejo — de 1988 - por el flanco izquierdo, pero también lo fueron para la generación de Jaime Bellolio —de 1980 - y Felipe Kast — de 1977— por la derecha. Estos últimos no son estrictamente millennials, pero su cohorte política es de todos modos 2011 céntrica. Ninguno de los dos, por ejemplo, tenía más de diez años al celebrarse el plebiscito de $1988 .{ }^{9}$

Siguiendo la distinción entre estrategias de renovación y reemplazo, los casos de Jaime Bellolio y Camila Vallejo - a los cuales habría que agregar a Karol Cariola, nacida en 1987- son típicos de renovación interna: representan el recambio en la Unión Demócrata Independiente (UDI) y el Partido Comunista (PC), respectivamente. Pero las otras figuras más representativas de la generación 2011 céntrica siguieron la vía del reemplazo: mientras Felipe Kast cofundó Evópoli, Giorgio Jackson cofundó Revolución Democrática (RD). En esta estrategia habría que agregar a Gabriel Boric — de 1986-, cofundador del Movimiento Autonomista (MA) ${ }^{10}$, así como a Vlado Mirosevic — de

${ }^{9}$ Morales y Reveco (2018) establecen una clasificación similar en Latinoamérica: los que votaron previo a los golpes de Estado de los años sesenta y setenta, los que no votaron previo a dichos golpes pero que sí tenían edad para votar en el plebiscito posterior o primeras elecciones democráticas, y los que no votaron en ninguna de aquellas instancias. En el caso chileno, todos estos últimos serían parte de la generación 2011 céntrica.

${ }^{10}$ En mayo del 2019, el MA se une a la Izquierda Libertaria (IL), Nueva Democracia (ND) y Socialismo y Libertad (SOL), todos del Frente Amplio, para fundar el nuevo partido Convergencia Social. 
1987-, que refundó el Partido Liberal de Chile (PL). En el marco de la estrategia del reemplazo de partidos cabe aun una distinción: mientras unos aspiran a renovar una coalición, otros aspiran a reemplazar una de las coaliciones existentes. Evópoli ejemplifica lo primero: constituye reemplazo a nivel de partidos, pero busca la renovación de una coalición existente, en este caso la vieja coalición heredera del SÍ a Pinochet. En tanto, RD, el MA y el PL constituyen reemplazo a nivel de partidos y reemplazo a nivel de coaliciones, pues forman el Frente Amplio en lugar de renovar la coalición heredera del No a Pinochet. Evópoli se muda de casa, pero no de barrio. RD se muda de casa $y$ de barrio. Esta diferencia, veremos, dificulta nuestra capacidad de medir el impacto de la variable generacional en forma transversal de izquierda a derecha.

\section{LA ELECCIÓN DE 2017}

Según esta historia, la efervescencia política del 2011 anima la formación de estructuras partidarias cuya primera línea pertenece a una generación cuyos marcos de referencia se desarrollan en democracia. Los casos más emblemáticos de la estrategia de reemplazo - RD por la izquierda y Evópoli por la derecha- nacen oficialmente en 2012. No alcanzan a competir en las municipales de ese año. ${ }^{11} \mathrm{Al}$ año siguiente, sin embargo, las figuras más representativas de la generación 2011 céntrica obtienen un escaño en la Cámara de Diputados: Felipe Kast y Giorgio Jackson por Santiago, Gabriel Boric por Punta Arenas, Camila Vallejo por La Florida, Karol Cariola por Independencia, Vlado Mirosevic por Arica y Jaime Bellolio por San Bernardo. Las elecciones municipales de 2016, sin embargo, temperan las esperanzas de renovación y reemplazo. El sistema de partidos de la transición no sufre abollones. La excepción más resonante es el triunfo de Jorge Sharp, del MA, en Valparaíso. Allí, una coalición integrada por fuerzas ciudadanas, pero animada políticamente por los movimientos que meses después darían vida al Frente Amplio, se impone sorpresivamente a las dos grandes coaliciones tradicionales.

${ }^{11}$ Aun así, en la comuna de Providencia, RD apoya a Josefa Errázuriz, la candidata que derrota en una mediática competencia al histórico alcalde UDI Cristián Labbé. 
En las presidenciales y parlamentarias de 2017, finalmente, la arremetida generacional se observa con mayor claridad a nivel nacional. La candidata del recientemente formado Frente Amplio, Beatriz Sánchez, alcanza - contra todos los pronósticos- el 20,27 por ciento de las preferencias, pisándole los talones al candidato oficialista de la Nueva Mayoría, Alejandro Guillier, quien obtiene 22,7 por ciento. A diferencia de Guillier, que fue proclamado candidato por los dirigentes de su coalición, Sánchez consiguió la nominación a través de un proceso democrático de primarias en las cuales derrotó al sociólogo Alberto Mayol. Aunque estuvo lejos de ser un éxito de participación — votaron 327.716 personas, contra 1.418 .138 de la coalición de derecha—, sirvió para que el Frente Amplio se posicionara ante la opinión pública como "la" alternativa de izquierda. El buen resultado de Sánchez en la presidencial tiene un correlato en el buen resultado de su lista parlamentaria, que obtiene 16,5 por ciento de los votos totales. Superando sus propias expectativas, el Frente Amplio conquista un escaño senatorial y veinte diputaciones. De aquéllas, diez son para RD, apenas cuatro menos que la histórica Democracia Cristiana (DC) y dos más que el Partido por la Democracia (PPD), la agrupación más identificada con la fisura generativa de 1988. Entre otros resultados llamativos, Giorgio Jackson obtiene primera mayoría en el nuevo distrito que incorpora las comunas de Santiago, Ñunoa, Providencia, La Granja, Macul y San Joaquín, uno de las más grandes del país con un padrón de casi un millón de personas. Le alcanza para arrastrar a dos compañeros de subpacto. En el extremo sur y en el extremo norte del país, respectivamente, Boric y Mirosevic consiguen cómodas reelecciones.

Por su parte, Evópoli elige dos senadores y seis diputados, también mejor que lo esperado. Meses antes, Felipe Kast había desafiado al propio Sebastián Piñera en la primaria del sector. En la parlamentaria, Felipe Kast obtiene la primera mayoría senatorial en La Araucanía. Cerca de alcanzar la primera mayoría también estuvo Francisco Undurraga en el nuevo distrito 11, que incluye las comunas donde se concentra el poder político y económico del país. En ambos casos se observa un descenso de la votación histórica de la UDI. Como integrante de la nueva coalición de gobierno, Evópoli obtiene dos carteras ministeriales: la Secretaría General de la Presidencia y Transportes. Menos exitosa fue la apuesta de la debutante coalición de centro liberal Sentido Futuro 
—integrada por los partidos Ciudadanos, Todos y Amplitud-, que no obtuvo representantes. ${ }^{12}$ Finalmente, según datos de una encuesta realizada a candidatos de todo el espectro político (Sajuria et al. 2017), los partidos que presentaron candidatos más jóvenes en la última elección de diputados fueron RD y el PL, ambos del Frente Amplio, con un promedio de 37 años cada uno. El promedio del Frente Amplio se elevó a 45 años. En la ex Nueva Mayoría, el promedio fue de 50,5 años. El PC llevó los candidatos más longevos $(51,1)$, seguido de la DC $(50,7)$ y el Partido Radical Socialdemócrata (PRSD, 50,1). Por su parte, el promedio de edad de los candidatos de Evópoli fue algo menor que el promedio de su coalición: 47 contra 49.

Ahora bien, ¿contribuyó esta arremetida generacional, representada por nuevos partidos y coaliciones, para revertir la crisis de representatividad que venía experimentando el sistema político chileno? Tenemos pocos datos concluyentes para afirmarlo, aunque sí existen algunos indicios de que la nueva oferta política fue más atractiva en sectores más jóvenes. Un reciente estudio, que aplica herramientas de big data sobre la base de datos públicos del Servicio Electoral respecto del padrón electoral de 2009 (tomando en cuenta que muy pocos chilenos se inscribieron en los registros entre 1988 y 2009) y del 2017, confirma que es posible constatar un quiebre generacional, al menos en la izquierda. Mientras lo que los autores llaman la "generación del plebiscito" votó mayoritariamente por los candidatos de la ex Nueva Mayoría, la "generación de la democracia" votó mayoritariamente por las candidatas y candidatos que ofreció el Frente Amplio (Huneeus et al. 2018). Si sólo hubiesen votado los segundos, afirman, Beatriz Sánchez habría obtenido casi un tercio de los votos y habría accedido a segunda vuelta en detrimento de Guillier. Estos datos son consistentes con otra reciente investigación, la que estima que el 44,4 por ciento de los estudiantes chilenos - principalmente menores de 30 años - habría votado por Beatriz Sánchez, contra el 29,9 por ciento que habría votado por Piñera y apenas el 7 por ciento por Guillier (Cox 2018).

12 El caso de Sentido Futuro es interesante, pues representaba un esfuerzo explícito por superar la división heredada de 1988. Mientras la trayectoria política de los dirigentes de Ciudadanos estaba asociada a la Concertación, la trayectoria política de los dirigentes de Amplitud estaba asociada a la coalición del Sí. Más allá de sus dirigentes, sus militantes más jóvenes interpretaron estos proyectos en clave 2011 céntrica. De hecho, Ciudadanos nace en 2013 y Amplitud, en 2014. 
Los datos de participación electoral entregan otra pista. A primera vista, las elecciones de 2017 marcaron el fin de la tendencia a la baja. Aunque sólo el 46,7 por ciento de la población en edad de votar lo hizo en la primera vuelta presidencial, en segunda vuelta la participación subió a 49,02 por ciento, siete puntos porcentuales más que en el balotaje de 2013. Para nuestro propósito, este dato no es muy útil, tomando en consideración que la segunda vuelta se disputó entre dos candidatos que no representaban renovación generacional. Más útil resulta comparar la participación electoral por segmento etario entre las parlamentarias de 2013 y 2017, en las que por primera vez desde el retorno de la democracia se registra un alza en las cohortes más jóvenes (cuadro 1).

Cuadro 1. PARTICIPACIÓN ELECTORAL POR SEGMENTO ETARIO EN ELECCIONES PARLAMENTARIAS 2013 Y 2017

\begin{tabular}{lrrrr}
\hline & $18-19$ & $20-24$ & $25-29$ & $30-34$ \\
\hline 2013 & $29,4 \%$ & $32,2 \%$ & $34,4 \%$ & $36,3 \%$ \\
\hline 2017 & $36 \%$ & $36 \%$ & $37,4 \%$ & $38,3 \%$ \\
\hline
\end{tabular}

Fuente: Servicio Electoral de Chile (Servel).

A partir de lo anterior, la especulación es que la nueva oferta política - principal pero no exclusivamente representada por los partidos que encarnan la estrategia del reemplazo - se encontró con una nueva demanda electoral, principal pero no exclusivamente representada por la población que no votó en el plebiscito de 1988. Es tarea de nuevos estudios empíricos demostrar o refutar que los jóvenes votaron por los candidatos y candidatas de los nuevos partidos y coaliciones. La hipótesis, en concreto, es que el Frente Amplio fue más atractivo que la Nueva Mayoría para la generación 2011 céntrica con sensibilidad de izquierda. La misma hipótesis podría plantearse respecto de Evópoli versus sus socios de coalición, aunque en este caso es más difícil determinarlo, tomando en cuenta que todos esos votos fueron a parar a la misma lista y que Evópoli tuvo que someterse a ciertas restricciones de cupos a nivel nacional.

En resumen, la fragmentación del paisaje político chileno, a primera vista, va aparejada de la irrupción de una nueva generación que se organiza políticamente bajo banderas propias. Estas banderas no se 
corresponden necesariamente al ordenamiento democrático-autoritario de la transición. La tesis del artículo es que el sistema de partidos muta, en parte, cuando la élite política de la generación post-Pinochet articula una oferta electoral propia y es capaz de movilizar a parte relevante del electorado. ${ }^{13}$ Las oportunidades que entrega el nuevo sistema electoral permiten que dicha estrategia sea relativamente exitosa y se traduzca en representación parlamentaria.

\section{EL NUEVO PAISAJE POLÍTICO CHILENO}

¿Qué fisura determina, entonces, al sistema chileno de partidos? Siguiendo a Tironi y Agüero (1999), hemos sostenido que el proceso de socialización política que aconteció a partir de la experiencia autoritaria y el plebiscito de 1988 tuvo la capacidad de absorber y sustituir a los grandes clivajes sociológicos pre-1973. Por casi tres décadas ininterrumpidas, organizó la competencia partidaria entre los herederos del Sí y del No a Pinochet. Sin embargo, la división democrático-autoritaria ha perdido tracción. Desde una perspectiva estrictamente institucional, hemos sostenido, las razones apuntan principalmente al fin del sistema binominal, el que perpetuaba dicho ordenamiento a través de incentivos y desincentivos electorales. Sin perjuicio de los factores institucionales, aquí hemos explorado una tesis complementaria: el reciente cambio en

${ }^{13}$ Estas nuevas élites no provienen de una extracción socioeconómica muy distinta a las élites de la transición. Varios de sus líderes pertenecen a familias ligadas a la política. Felipe Kast es hijo del fallecido economista gremialista Miguel Kast, ex ministro de la dictadura. Hernán Larraín Matte, actual presidente de Evópoli, es hijo de Hernán Larraín Fernández, dirigente histórico de la UDI. Respecto del Frente Amplio, la ex Presidenta Michelle Bachelet señaló que "los jóvenes del Frente Amplio son hijos de militantes de partidos tradicionales" (fuente: https://www.emol.com/noticias/Nacional/2017/06/15/862780/Michelle-BacheletEn-general-los-jovenes-del-Frente-Amplio-son-hijos-de.html). La expresión no es metafórica, sino literal. Varios de los líderes del Frente Amplio son hijos de ex colaboradoras de la propia Bachelet. El diputado de RD Miguel Crispi es hijo de la ex ministra socialista Claudia Serrano. Nicolás Grau, coordinador programático de la candidatura presidencial de Beatriz Sánchez y militante del MA, es hijo de la ex ministra socialista Paulina Veloso. Camilo Riffo, candidato a diputado del MA en Concepción, es hijo de la ex ministra socialista Paula Quintana. Algunos de estos dirigentes alcanzaron a militar brevemente en partidos tradicionales (Larraín Matte en Renovación Nacional (RN), Crispi en el Partido Socialista), a los cuales renunciaron para colaborar en la fundación de los propios. 
el paisaje político chileno se explica a partir del vencimiento del eje del plebiscito ante los ojos de una generación que construyó sus marcos de referencia en democracia. Al tratarse de un hito retrospectivo, las élites políticas interesadas en su vigencia van perdiendo la capacidad de ofrecer coordenadas de pertenencia para quienes no experimentaron dicho proceso de socialización.

La reciente conmemoración del trigésimo aniversario del plebiscito ilustra el punto: mientras la generación 88 céntrica intentó revivir la épica de la recuperación de la democracia a través de una serie de actos y declaraciones públicas, la generación 2011 céntrica participó sólo en calidad de comparsa. Para los jóvenes elencos dirigentes del Frente Amplio, revivir el clivaje del plebiscito implica aceptar la vigencia de las mismísimas figuras que aspiran a suceder en la primera línea política. Para los jóvenes elencos dirigentes de Evópoli, revivir el clivaje del plebiscito significa traer de regreso la incómoda sombra de Pinochet.

Éste no es el único problema para la centroizquierda de la transición. La centroderecha mainstream también está siendo relativamente efectiva en separarse de la experiencia autoritaria. El triunfo de Sebastián Piñera en 2010 fue el primer indicio. En 2013, al cumplirse 40 años del golpe militar, Piñera denunció a los "cómplices pasivos" de la dictadura. ${ }^{14}$ Aun así, la derecha se dividió y algunos interpretaron que el episodio había sido propicio para revivir la fisura democrático-autoritaria (Aubry y Dockendorff, 2014). En 2018, nuevamente desde La Moneda, Piñera encabezó la conmemoración de los 30 años del plebiscito. En su narrativa revisionista, el hito de 1988 debía ser reivindicado por todos los sectores, en tanto había inaugurado una transición ejemplar del autoritarismo a la democracia. Sin perdedores, sólo ganadores. Aunque también hubo voces disidentes, esta vez la mayoría de la derecha agrupada en Chile Vamos respaldó la tesis de Piñera. En clave gramsciana, la opción por la democracia se convirtió en la opción hegemónica. Se hizo difícil encontrar políticos que públicamente defendieran la opción de la continuidad de Pinochet. Más todavía, algunas de las figuras más emblemáticas tanto de la estrategia de la renovación como del reemplazo en la derecha llamaron a condenar sin matices, ni justificaciones, ni con-

14 Fuente: https://www.latercera.com/noticia/presidente-sebastian-pinera-ysu-juicio-a-40-anos-del-golpe-hubo-muchos-que-fueron-complices-pasivos-quesabian-y-no-hicieron-nada-o-no-quisieron-saber/. 
textos, la dictadura militar. ${ }^{15}$ En este marco, un sondeo realizado en septiembre de 2018 arrojó que el 70 por ciento de la ciudadanía votaría por la opción No si el referendo sobre la continuidad de Augusto Pinochet se llevara a cabo en la actualidad. Apenas el 18 por ciento señaló que votaría Sí. ${ }^{16}$ En síntesis, la opción por la democracia parece imponerse en forma tan clara por sobre la opción del autoritarismo, que pierde algo de sentido seguir dividiendo a la población en base a ese ordenamiento. Son los paradójicos costos de la hegemonía: la centroizquierda gana, pero, al convertir a sus adversarios al credo democrático, diluye las coordenadas que le permitían dividir el mundo entre ellos y nosotros.

El debilitamiento de la fisura del plebiscito como elemento explicativo del mapa político chileno no equivale a su desaparición. La variable generacional impacta en el sistema de partidos, pero no lo define enteramente. En el escenario post-2017, ambas variables coexisten. En este sentido, si la división democrático-autoritaria no es un clivaje en el sentido canónico, sino que obedece al resultado de posicionamientos contingentes a partir de un determinado proceso político de socialización, lo mismo podría decirse de la variable generacional. En rigor, no existe un clivaje generacional, pues la población chilena no se divide políticamente entre jóvenes y viejos. Los jóvenes que irrumpen a partir del proceso de socialización desatado en 2011 no se agrupan en el mismo partido ni en la misma coalición. RD y Evópoli, los casos más representativos, no están en el mismo bando en el sistema de partidos. Si bien es cierto que en algunos episodios han dejado entrever un espíritu de validación generacional, esto ha sido principalmente por motivos tácticos. Del mismo modo, los elencos de la transición no se agrupan bajo el mismo paraguas. Por tanto, la variable generacional no constituye un clivaje propiamente tal, ni tampoco es suficiente para explicar por sí sola el nuevo paisaje político. Pero sí contribuye a su entendimiento.

${ }^{15}$ Principalmente el diputado UDI Jaime Bellolio y el presidente de Evópoli, Hernán Larraín Matte. Otros, como el diputado de Evópoli Francisco Undurraga y el diputado de RN Sebastián Torrealba asistieron al acto oficial de la conmemoración del triunfo del No en Santiago. La excepción que confirma la regla es el caso de la joven diputada RN Camila Flores — nacida en 1987-, quien se ha declarado abiertamente pinochetista. Sus expresiones han sido motivo de revuelo público justamente porque se creía, al menos en las nuevas generaciones, una etapa superada.

16 Fuente: https://www.latercera.com/politica/noticia/estudio-senala-plebiscito-fuese-hoy-70-votaria-no/336832/\#. 
Por el lado izquierdo, como hemos visto, se percibe una fractura generacional tanto a nivel de élites políticas como de su electorado. Por el lado derecho, se advierte un cierto quiebre generacional a nivel de élites - lo que explica el nacimiento de Evópoli-, pero aún no sabemos si ello conlleva además una grieta en su electorado. Al optar por la estrategia de reemplazo partidario, pero renovación coalicional, los votos de Evópoli se confunden con los de sus socios herederos del Sí. Aun así, es plausible suponer que, del mismo modo que los jóvenes de centroizquierda se sienten biográficamente más cercanos a RD que al PPD, los jóvenes de centroderecha se sientan biográficamente más cercanos a Evópoli que a la UDI. ${ }^{17}$ Esta tesis ya cuenta con suficientes antecedentes a nivel universitario. ${ }^{18}$

Ahora bien, RD y Evópoli no pueden considerarse como una mera reedición del eje democrático-autoritario. Como hemos sugerido, Evópoli no puede ser ubicado en el lado autoritario de dicho ordenamiento. En primer lugar, porque generacionalmente no fue parte de dicho proceso de socialización. En segundo lugar, porque sus credenciales son

${ }^{17}$ Según ha investigado Stéphanie Alenda (2017), si bien la militancia de Evópoli coincide con la militancia de la UDI y RN en los debates socioeconómicos, se distancia del conservadurismo de sus socios en las llamadas materias "valóricas". Una reciente radiografía al Congreso realizada por la Universidad Diego Portales confirma lo anterior: los congresistas de Evópoli conjugan liberalismo económico y valórico (fuente: https://www.latercera.com/reportajes/noticia/cuan-liberales-loscongresistas/395347/). Si a esto le sumamos la evidencia de que las nuevas generaciones de chilenos son más liberales — en lo moral — que sus padres (Luna 2008), entonces es razonable especular que Evópoli representa mejor las sensibilidades de los millennials de su sector.

${ }^{18}$ En las universidades más emblemáticas del país, la disputa por las federaciones estudiantiles ya no se da entre las juventudes de los partidos políticos de la transición — quizás con la sola excepción del PC—, sino entre facciones universitarias de las nuevas fuerzas políticas nacionales. La Federación de Estudiantes de la Universidad de Chile (FECh) ha sido conducida en los últimos años por movimientos que integran el Frente Amplio, como el MA, el Frente de Estudiantes Libertarios (FEL) y la Unión Nacional Estudiantil (UNE). La Federación de Estudiantes de la Universidad Católica (FEUC) ha sido dirigida principalmente por la agrupación Nueva Acción Universitaria (NAU), que funciona como semillero de RD. Los diputados Miguel Crispi y Giorgio Jackson, por ejemplo, presidieron la FEUC representando al NAU. En instituciones privadas como la Universidad Adolfo Ibáñez, se registra alternancia entre representantes estudiantiles de RD y Evópoli. Este dato es relevante, tomando en cuenta la importancia histórica del movimiento estudiantil en el devenir político chileno. 
impecablemente democráticas. Sin embargo, sí se puede sostener que tanto RD como Evópoli se identifican, respectivamente, con una idea general de izquierda y de derecha, al menos si estas categorías sirven para responder a las clásicas preguntas respecto del rol del Estado y del mercado. Sin ir más lejos, el hito de origen de la arremetida generacional - las movilizaciones de 2011 - giró en torno a estos imperecederos debates. Si bien la discusión específica abordó el lucro y la gratuidad universitaria, la temática educacional fue un proxy para debatir sobre el modelo de desarrollo. No es sorpresivo que dichas demandas hayan escalado hasta la cuestión constituyente. De esta manera se configuró una línea divisoria en las élites de la nueva generación: los que estaban a favor y los que estaban en contra del discurso del movimiento estudiantil. Mientras los futuros fundadores de RD marchaban en las calles, los futuros fundadores de Evópoli debutaban en el gobierno de Sebastián Piñera. ${ }^{19}$ Por cierto, a diferencia de lo que ocurrió en 1988, las definiciones de 2011 eran mucho menos nítidas. No obstante, fue posible identificar dos miradas sobre el modelo chileno. Mientras los futuros líderes del Frente Amplio se nutrieron del relato de derechos sociales que articularon intelectuales como Fernando Atria, Claudia Sanhueza y Alberto Mayol, los futuros líderes de Evópoli se resistieron a demandas que consideraron normativamente injustas, y pidieron invertir la preocupación desde los universitarios hacia los niños. Por resumirlo de alguna manera, el eje izquierda-derecha de la nueva generación quedó definido en clave sandeliana (a propósito de la obra del teórico político Michael Sandel (2013) y su atención respecto a qué puede y qué no puede comprar el dinero). Mientras la izquierda proponía sustraer de las reglas del mercado algunos accesos a bienes y servicios fundamentales para gozar de un estatus de igual ciudadanía - como educación y salud-, la derecha estimaba que dichos mercados no sólo permitían el despliegue de la libertad, sino que sus diferenciales accesos se justificaban en función del esfuerzo y el mérito personal, dentro del marco de una razonable igualdad de oportunidades.

Respecto de estas alineaciones ideológicas, Cox (2018) observa una contradicción: si bien el discurso del Frente Amplio y de su candidata presidencial parecía radical y autoflagelante respecto del legado de

${ }^{19}$ Esto explica en parte los diez años de diferencia que tuvieron, en promedio, los candidatos de RD y Evópoli. 
la Concertación, un porcentaje importante - casi el 40 por ciento- de los jóvenes que dijeron adherir a Beatriz Sánchez se declaró independiente o de ninguna tendencia, incluso con algunos identificándose con el centro y la derecha. Tampoco encontró Cox que fueran, en promedio, particularmente críticos de la Concertación. En otras palabras, a diferencia de lo que ocurría con Piñera - cuyo votante joven resultó ser mucho más duro y consistente ideológicamente-, el votante joven de Sánchez resultó ser menos ideologizado de lo que pudiera pensarse. No hay entre los votantes jóvenes de Sánchez, concluye Cox, "una visión radical a favor de un rol más fuerte para el Estado o la igualdad. Así, tanto por autoidentificación como por posiciones en temas relevantes, el estudiante que votó por Sánchez no sería un votante duro de izquierda" $(2018,12)$. Sin embargo, esta contradicción es solo aparente respecto de la tesis de este artículo, que insiste justamente en la importancia de factores no ideológicos en la conformación del nuevo paisaje político. La investigación de Cox sostiene que en las preferencias juveniles por Piñera pesó más la ideología mientras en las preferencias juveniles por Sánchez pesaron factores más transversales. Mi tesis es que esos factores están íntimamente ligados a la promesa de renovación. Los jóvenes de derecha votaron por el candidato de derecha, pero los jóvenes en general se inclinaron mayoritariamente por la candidata que representaba a su generación. ${ }^{20}$

Lo que concluye Cox, entonces, es perfectamente compatible con mi tesis: el Frente Amplio fue capaz de conectarse con la mayoría relativa de la nueva generación, trascendiendo las fronteras de lo que podría considerarse ideológicamente la izquierda. Si bien muchos chilenos votaron por Beatriz Sánchez y los candidatos del Frente Amplio debido a sus ideas de izquierda, otros tantos lo hicieron porque representaban renovación y frescura, especialmente en el contexto del descalabro reputacional de los elencos de la transición a partir de los casos de corrupción conocidos en el segundo gobierno de Bachelet. En este sen-

${ }^{20}$ Si bien Beatriz Sánchez no es una millennial en sentido estricto, sino más bien una representante de la llamada Generación X, no tenía edad para votar en el plebiscito de 1988. Es decir, al igual que Felipe Kast, cae dentro de la categoría que hemos denominado 2011 céntrica. El ascenso de Sánchez como voz política, a través de sus diversas tribunas de opinión y periodísticas, coincide también con el despertar político de la generación de Jackson y Boric, que la "ungen" como su candidata para las primarias del Frente Amplio. 
tido, sus propios dirigentes declararon que la suya no era una coalición de izquierda "sino más bien ciudadana". ${ }^{21}$ En lo ideológico, la inclusión del PL le ha permitido al Frente Amplio sostener que no está integrado solamente por partidos y movimientos anticapitalistas. En otras palabras, sus líderes comprendieron que sus perspectivas electorales no podían depender de su radicalidad doctrinaria, sino que tenían que vincularse con la novedad incontaminada de sus elencos. Es una estrategia consistente con la tesis del rol de la agencia política en la activación y desactivación de los clivajes, entendidos en forma genérica. El Frente Amplio se posicionó simultáneamente como una fuerza joven en el eje generacional y como una fuerza de izquierda en el eje ideológico. Dependiendo de la necesidad, subrayó uno u otro. ${ }^{22}$

Cox se pregunta si acaso la idea de una juventud de izquierda en Chile no se debe acaso al "reflejo de un grupo minoritario de jóvenes que han logrado construir exitosamente una opción política y que tienen, además, una narrativa y una alta figuración mediática" $(2018,12)$. Es muy posible que sea así. Pero eso no obsta a que la élite dirigente del Frente Amplio tenga efectivamente convicciones de izquierda en la clave sandeliana descrita. Desde el punto de vista de las élites, las movilizaciones del 2011 fueron útiles para actualizar el eje ideológico izquierda-derecha en torno a la legitimidad social del lucro, desanclándolo parcialmente del eje democrático-autoritario en el cual había quedado absorbido. Así se entiende, por ejemplo, que intelectuales y technopols fuertemente identificados con el campo democrático de la fisura plebis-

21 Fuente: https://radio.uchile.cl/2017/03/28/voceros-del-frente-amplio-afirman-que-no-son-una-coalicion-de-izquierda-sino-mas-bien-ciudadana/.

22 Tal como les ocurrió a las élites de la Concertación, las élites del Frente Amplio se verán también en la necesidad de alimentar la vigencia del hito originario de 2011, reponiéndolo cada cierto tiempo en la memoria. Así se explica, en parte, la relación entre el Frente Amplio y las movilizaciones feministas de 2018. En circunstancias de que las demandas centrales del movimiento estudiantil de 2011 han sido procesadas por el sistema político (gratuidad universitaria, fin del lucro, selección y copago en la educación escolar, desmunicipalización), a la nueva izquierda le resulta difícil revivir aquella efervescencia. A esto se suma que los principales líderes del 2011 están en el espacio institucional que representa el Congreso. La movilización feminista les dio la posibilidad de reconectarse con el espíritu de rebeldía de la calle, y extender de esa manera el recuerdo del hito originario de 2011. Como lo expresó la escritora Arelis Uribe en su cuenta de twitter: el 2018 es el 2011 feminista. 
citaria - Carlos Peña, José Joaquín Brunner, Andrés Velasco y el propio Eugenio Tironi, entre otros - fueran al mismo tiempo detractores de las demandas del movimiento estudiantil y de la izquierda 2011 céntrica. Para la izquierda millennial del Frente Amplio, haber estado en el bando democrático de la transición no basta. Por el contrario, la élite frenteamplista sí critica duramente el legado de la Concertación y lo que según ellos fue una mera administración de la obra de la dictadura. De hecho, obligan a la generación de la transición a radicalizarse: en la campaña presidencial de 2013, Michelle Bachelet toma como propias las banderas del movimiento estudiantil. ${ }^{23}$ Por su parte, Evópoli se distancia del resto de la derecha 88 céntrica si de la fisura plebiscitaria se trata, pero comparte ideológicamente con sus socios de Renovación Nacional (RN) y la UDI si la línea divisoria se presenta en la clave sandeliana descrita.

Este proceso de actualización ideológica de las élites políticas sugiere al menos dos cosas. Primero, que es posible fundar un ordenamiento izquierda-derecha con relativa independencia del eje democrático-autoritario del plebiscito y la posterior transición. Y segundo, que la variable generacional no puede ser entendida como un nuevo eje que separa aguas entre jóvenes y viejos, pues persisten fuertes diferencias ideológicas entre las fuerzas jóvenes que emergen del proceso de socialización de 2011. Este proceso gatilla una reflexión ideológica que actualiza los criterios de izquierda y derecha que habían quedado subsumidos en el eje democrático-autoritario. La fisura de 1988 persiste principalmente para las generaciones que votaron en el plebiscito, pero pierde influencia para determinar la posición relativa de los actores, establecer las pertenencias partidarias y dictar las lógicas coalicionales en el nuevo mapa político. En las generaciones que no votaron en el plebiscito, otras coordenadas adquieren relevancia. Un veinteañero políticamente consciente que favorece la idea de derechos sociales se encuentra, probablemente, dentro de la esfera de influencia del Frente Amplio. Un veinteañero políticamente consciente que favorece criterios de mercado para determinar la distribución de recompensas sociales se

${ }^{23}$ En su primera actividad tras retornar de Nueva York en abril de 2013, Bachelet confiesa que le parece injusto que su hija vaya gratis a la universidad si ella puede pagársela. Nunca más volvió a decirlo. Muy probablemente, fue conminada a seguir al pie de la letra la pauta de las demandas del movimiento estudiantil, las cuales luego incorporó íntegramente en su programa. 
encuentra, probablemente, dentro de la esfera de influencia de Evópoli. Para la mayoría de ellos, la fisura de 1988 no es determinante a la hora de fijar su domicilio dentro del sistema de partidos.

A primera vista, a propósito del debilitamiento del eje democrático-autoritario, tampoco reaparecieron los clivajes sociales pre-1973. La religión no parece ser un factor determinante, toda vez que hay liberales "valóricos" y partidos seculares en prácticamente todas las coaliciones. Aunque la derecha, en teoría, agrupa las sensibilidades más religiosas, dicho patrón no se replica en Evópoli (Alenda et al. 2019). Desde el punto de vista de la clase, no se puede afirmar que la dirigencia del Frente Amplio provenga de las capas populares u obreras, sino más bien de estratos socioeconómicos medio-altos. De ahí su penetración en jóvenes profesionales y estudiantes universitarios. Siguiendo la lógica de Valenzuela (1999), entonces, es posible especular que este nuevo sistema de partidos no emerge por la acción de clivajes sociales estructurales que dividen profundamente a la población, sino por procesos de socialización política que se combinan y superponen. En la medida en que el proceso de socialización que Tironi y Agüero condensaron en su teoría de la fisura democrático-autoritaria se difumina en el tiempo, una nueva generación reclama el derecho de construir su propia oferta electoral a partir de su experiencia histórica, que se configura esta vez en torno a las movilizaciones de 2011. Por el lado de la izquierda, por primera vez en treinta años, al menos dos coaliciones se disputan el mismo espacio: mientras las élites de la transición siguen contando con la fidelidad de las generaciones que fueron políticamente socializadas en el período autoritario, el novel frenteamplismo ha sido más atractivo para las generaciones políticamente socializadas en democracia. Por el lado de la derecha, Evópoli se origina como alternativa a los partidos que nacieron para defender la obra de la dictadura, constituyéndose en el primer partido auténticamente post-Pinochet del sector.

Aunque la variable generacional explorada tiene un poder explicativo limitado, en tanto el sistema de partidos no se configura a partir de una división entre la generación del plebiscito, por un lado, y la generación de la democracia, por el otro, mientras subsisten profundas diferencias ideológicas al interior de la generación 2011 céntrica, sí entrega claves para comprender el nuevo paisaje político. Como toda consideración generacional, sobre todo cuando va asociada a un hito retrospectivo, también está destinada a diluirse en el tiempo. 


\section{REFERENCIAS}

Alenda, S. 2017. "La derecha perdida". El Mostrador, 27 octubre.

Alenda, S., C. Le Foulon \& S. del Hoyo. 2019. Evolución política y la renovación liberal en Chile. Santiago: Fondo de Cultura Económica.

Aubry, M. \& A. Dockendorff. 2014. “Cuarenta años no son nada: ¿la reposición del clivaje autoritarismo-democracia en el sistema de partidos chileno?" Revista de Sociología 29: 9-36.

Bargsted, M. \& N. Somma. 2016. "Social cleavages and political dealignment in contemporary Chile, 1995-2009”. Party Politics 22 (1): 105-124.

Bargsted, M., N. Somma \& B. Muñoz. 2018. "Participación electoral en Chile: Una aproximación de edad, período y cohorte". Revista de Ciencia Política (aceptado, por publicarse).

Bellolio, C. 2013. Renovación y reemplazo: Por qué el recambio politico es urgente en Chile. Santiago: Planeta.

Bidegain, G. 2016. "Informe especial: Movimiento estudiantil chileno: la despartidización y la politización pueden ir de la mano". En Cultura política de la democracia en Chile y en las Américas, 2014: ¿Tiempo de reformas?, editado por S. Toro, C. Acevedo \& N. Jaramillo-Brun, 113-114. Nashville: Vanderbilt University.

Bunker, K. 2018. "La elección de 2017 y el fraccionamiento del sistema de partidos en Chile". Revista Chilena de Derecho y Ciencia Politica 9 (2): 204-229.

Carey, J. 2002. "Parties, Coalitions, and the Chilean Congress in the 1990s". En Legislative Politics in Latin America, editado por S. Morgenstern \& B. Nacif, 222-253. Cambridge: Cambridge University Press.

Contreras, G. \& P. Navia. 2013. "Diferencias generacionales en la participación electoral en Chile, 1988-2010”. Revista de Ciencia Politica 33 (2): 419-441.

Cox, L. 2018. "Juventud y política a 30 años del plebiscito". Puntos de Referencia 497. Santiago: Centro de Estudios Públicos.

Cox, L., \& R. González. 2016. "Cambios en la participación electoral tras la inscripción automática y el voto voluntario". CEP Debates de Política Pública 14.

Duverger, M. 1954. Political Parties: Their Organization and Activity in the Modern State. Londres: Methuen.

Garrido, C. \& P. Navia. 2005. "Candidatos fuertes en la Concertación”. Estudios Públicos 99: 165-194.

Guzmán, E. 1993. "Reflexiones sobre el sistema binominal”. Estudios Públicos 51: 303-325.

Hooghe, L. \& G. Marks. 2018. "Cleavage Theory Meets Europe's Crises: Lipset, Rokkan, and the Transnational Cleavage". Journal of European Public Policy 25 (1): 109-135.

Huneeus, C., S. Acuña, I. Badal \& A. Díaz. 2018. "La Generación del Plebiscito, aún decisiva 30 años después". La Segunda, 3 de octubre. 
Krosnick, J. \& D. Alwin. 1989. "Aging and Susceptibility to Attitude Change". Journal of Personality and Social Psychology 57 (3): 416-425.

Lipset, S. M. \& S. Rokkan. 1967. "Cleavage Structures, Party Systems, and Voter Alignments: An Introduction”. En Party Systems and Voter Alignments: Cross National Perspectives, editado por S. M. Lipset \& S. Rokkan. Nueva York: The Free Press.

Luna, J. P. 2008. "Partidos políticos y sociedad en Chile. Trayectoria histórica y mutaciones recientes". En Reforma de los Partidos Politicos en Chile, editado por A. Fontaine et al. 75-124. Santiago: PNUD, CEP y Cieplan.

Luna, J. P. \& D. Altman. 2011. "Uprooted but Stable: Chilean Parties and the Concept of Party System Institutionalization". Latin American Politics and Society 53 (2): 1-28.

Morales, M. \& B. Reveco. 2018. "El efecto de las generaciones políticas sobre la participación electoral. El caso de Chile, 1999-2013”. Revista Perfiles Latinoamericanos 26 (52): 1-27.

Navia, P. 2004. "Participación electoral en Chile, 1988-2001". Revista de Ciencia Politica 24 (1): 81-103.

Ortega, Eugenio. 2003. "Los partidos políticos chilenos: Cambio y estabilidad en el comportamiento electoral 1990-2000”. Revista de Ciencia Política XXIII (2): 109-147.

Raymond, C. \& B. Feltch. 2014. "Parties, Cleavages and Issue Evolution: The Case of the Religious-Secular Cleavage in Chile”. Party Politics 20 (3): 429-443.

Sajuria, J., I. Mackinnon, R. Jeria \& J. Morillo. 2017. "Candidaturas Chile: Datos candidaturas al Congreso Chile v. 1.0". Harvard Dataverse. https://doi. org/10.7910/DVN/MIRQMB.

Sandel, M. 2013. Lo que el dinero no puede comprar. Los límites morales del mercado. Buenos Aires: Debate.

Scully, T. 1992. Los partidos de centro y la evolución política chilena. Santiago: Cieplan-Notre Dame.

Scully, T. \& S. Valenzuela. 1993. "De la democracia a la democracia: Continuidades y cambios en las opciones electorales y el sistema de partidos en Chile”. Estudios Públicos 51: 195-228.

Smets, K. \& C. van Ham. 2013. "The Embarrassment of Riches? A Meta-Analysis of Individual-Level Research on Voter Turnout”. Electoral Studies 32 (2): 344-359.

Tironi, E. 2010. Radiografía de una derrota, o cómo Chile cambió sin que la Concertación se diera cuenta. Santiago: Uqbar.

Tironi, E. \& F. Agüero. 1999. “SSobrevivirá el nuevo paisaje político chileno?”. Estudios Públicos 74: 151-168.

Torcal, M. \& S. Mainwaring. 2003. "The Political Recrafting of Social Bases of Party Competition: Chile, 1973-1995”. British Journal of Political Science 33 (1): $55-84$.

Toro, S. 2008. "De lo épico a lo cotidiano: Jóvenes y generaciones políticas en Chile". Revista de Ciencia Política 28 (2): 143-160. 
2016. "Movilización partidaria y electoral”. En Cultura política de la democracia en Chile y en las Américas, 2014: ¿Tiempo de reformas?, editado por S. Toro, C. Acevedo \& N. Jaramillo-Brun, 115-126. Nashville: Vanderbilt University.

Valenzuela, S. 1995. "Orígenes y transformaciones del sistema de partidos en Chile”. Estudios Públicos 58: 5-77.

. 1999. "Reflexiones sobre el presente y futuro del paisaje político chileno a la luz del pasado". Estudios Públicos 75: 273-290.

Valenzuela, S., T. Scully \& N. Somma. 2007. "The enduring presence of religion in Chilean ideological positionings and voter options". Comparative Politics 40 (1): 1-20. EP 